Supporting Information

\title{
Super-Hydrophobic Cellulose Nanofibers Air Filter with Highly Efficient Filtration and Humidity

\author{
Resistance
}

Tao Liu, Chenchen Cai, Ruijia Ma, Yongfei Deng, Lingyun Tu, Yifeng Fan, Dengjun Lu*

School of Light Industry and Food Engineering, Guangxi University, Nanning 530004, China

* Corresponding Author

E-mail: dj6688@126.com 

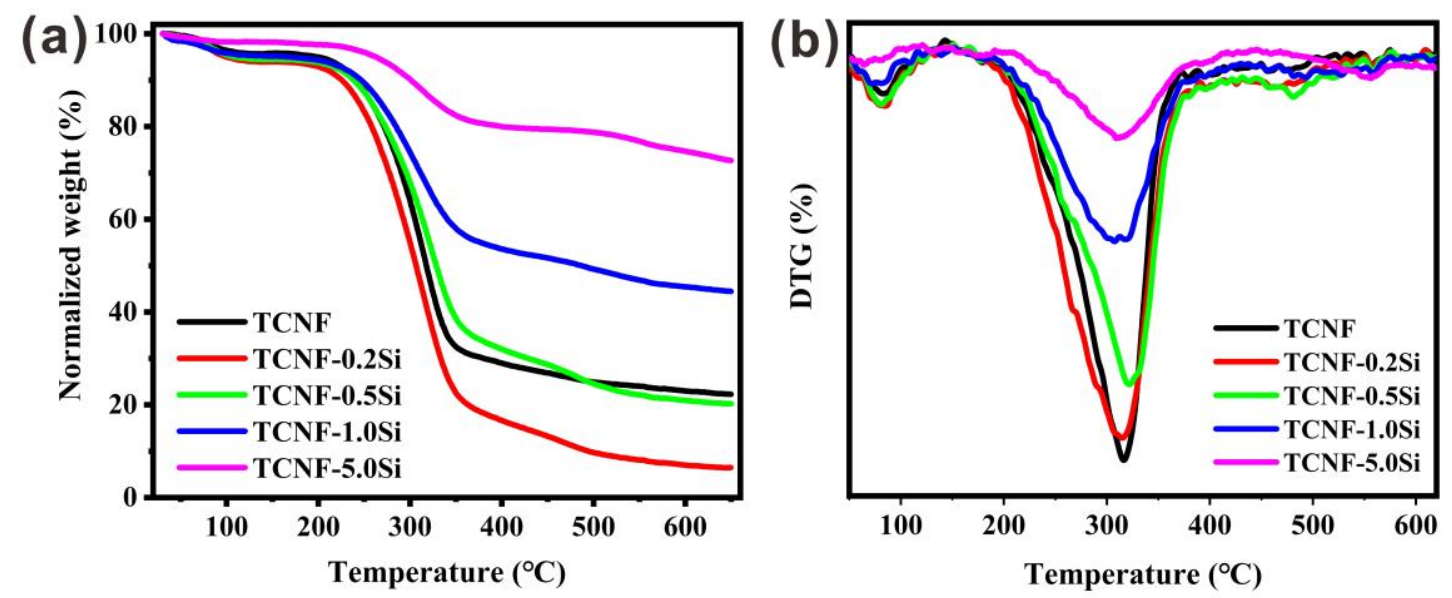

Figure S1. Thermal decomposition analysis of filters with different degrees of silanization. (a) TG; (b) DTG.

Table S1. Material ratio and physical and chemical indicators of filter.

\begin{tabular}{lcccccccc}
\hline Samples & $\begin{array}{c}\text { CNF/ } \\
\mathbf{w t} \%\end{array}$ & $\begin{array}{c}\text { TBA/ } \\
\mathbf{w t} \%\end{array}$ & $\begin{array}{c}\text { MTMS } \\
/ \mathbf{w t} \%\end{array}$ & $\begin{array}{c}\text { Weight } \\
/ \mathbf{g}\end{array}$ & $\begin{array}{c}\boldsymbol{\rho} / \\
\mathbf{g} \cdot \mathbf{c m}^{-3}\end{array}$ & $\begin{array}{c}\text { Porosity } \\
\text { factor } \\
/ \%\end{array}$ & $\begin{array}{c}\text { BET / } \\
\mathbf{m}^{2} \cdot \mathbf{g}^{-1}\end{array}$ & $\begin{array}{c}\text { Adhesion } \\
\text { work/ } \\
\mathbf{J} \cdot \mathbf{m}^{-2}\end{array}$ \\
\hline TCNF & $\mathbf{6 0 . 0}$ & $\mathbf{4 0 . 0}$ & $\mathbf{0}$ & $\mathbf{0 . 0 9 0 2}$ & $\mathbf{0 . 0 1 3 8}$ & $\mathbf{9 9 . 0 8 0}$ & $\mathbf{1 6 . 5 7 6}$ & $\mathbf{0}$ \\
TCNF-0.2Si & $\mathbf{6 0 . 0}$ & $\mathbf{3 9 . 8}$ & $\mathbf{0 . 2}$ & $\mathbf{0 . 1 0 0 6}$ & $\mathbf{0 . 0 1 1 9}$ & $\mathbf{9 9 . 2 1 2}$ & $\mathbf{2 4 . 7 6 8}$ & $\mathbf{0 . 0 0 1 1 9}$ \\
TCNF-0.5Si & $\mathbf{6 0 . 0}$ & 39.5 & $\mathbf{0 . 5}$ & $\mathbf{0 . 1 0 6 1}$ & $\mathbf{0 . 0 1 2 3}$ & $\mathbf{9 9 . 1 9 2}$ & $\mathbf{2 6 . 5 4 0}$ & $\mathbf{0 . 0 0 1 2 3}$ \\
TCNF-1.0Si & $\mathbf{6 0 . 0}$ & $\mathbf{3 9 . 0}$ & $\mathbf{1 . 0}$ & $\mathbf{0 . 1 3 0 7}$ & $\mathbf{0 . 0 1 5 1}$ & $\mathbf{9 9 . 0 0 9}$ & $\mathbf{1 4 . 6 5 4}$ & $\mathbf{0 . 0 0 1 3 3}$ \\
TCNF-5.0Si & $\mathbf{6 0 . 0}$ & $\mathbf{3 5 . 0}$ & $\mathbf{5 . 0}$ & $\mathbf{0 . 2 9 5 8}$ & $\mathbf{0 . 0 2 9 9}$ & $\mathbf{9 8 . 1 2 3}$ & 7.914 & $\mathbf{0 . 0 0 1 3 7}$ \\
\hline
\end{tabular}




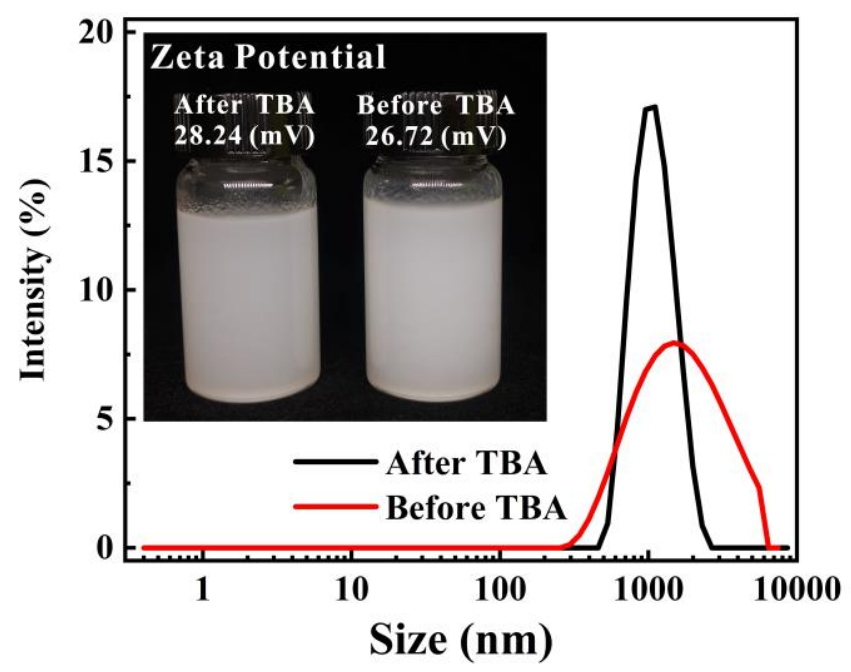

Figure S2. Zate potential and particle size distribution of CNFS solution before and after added TBA.

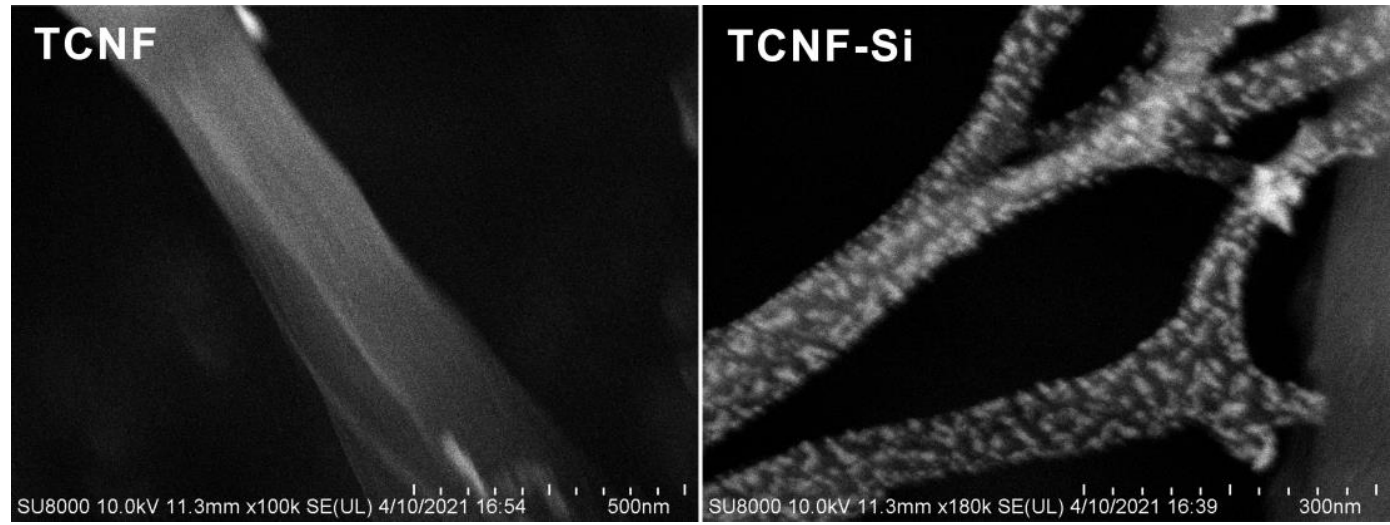

Figure S3. FE-SEM of TCNF and TCNF-Si. 


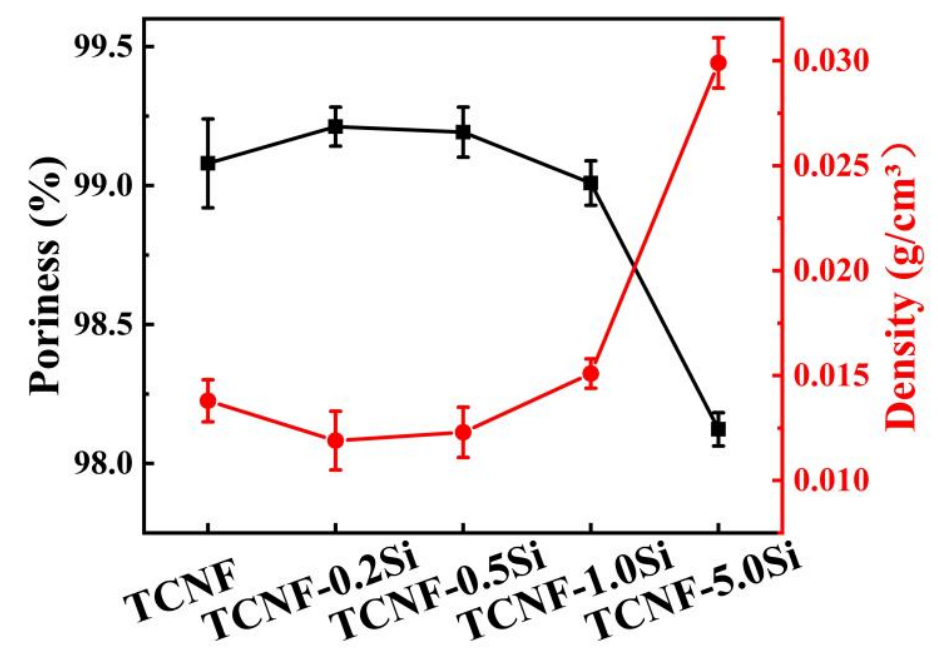

Figure S4. Porosity and density of air filter.
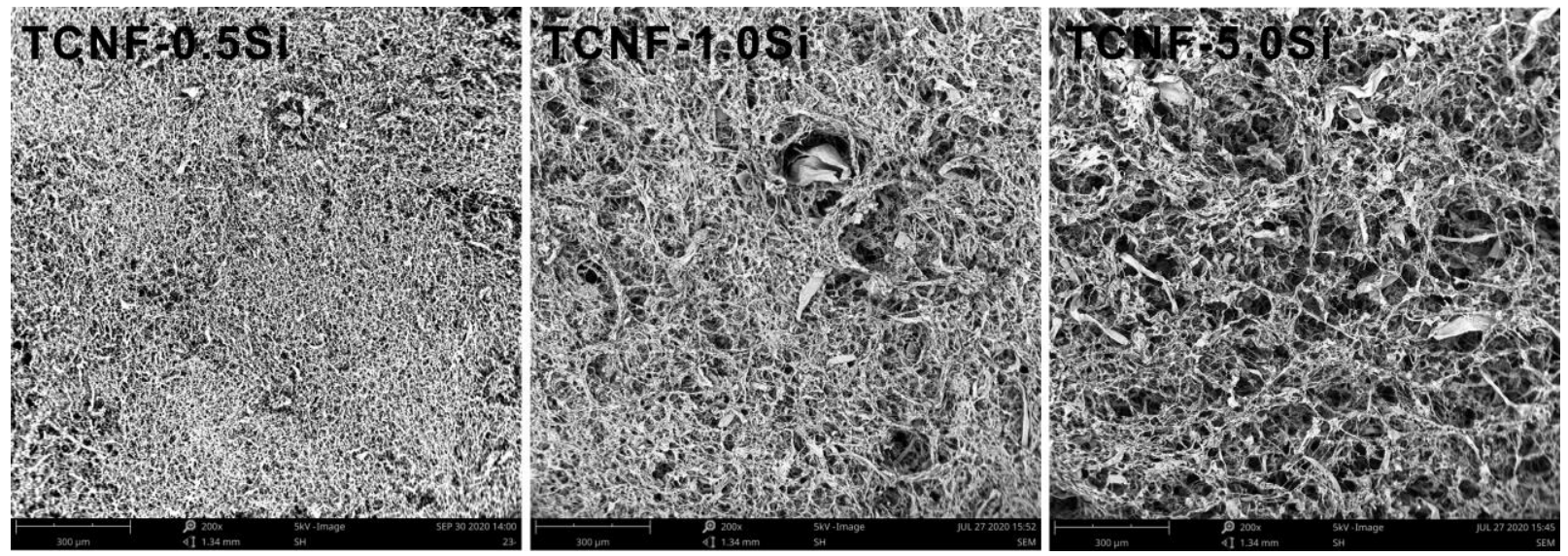

Figure S5. SEM of TCNF-0.5Si, TCNF-1.0Si and TCNF-5.0Si. 


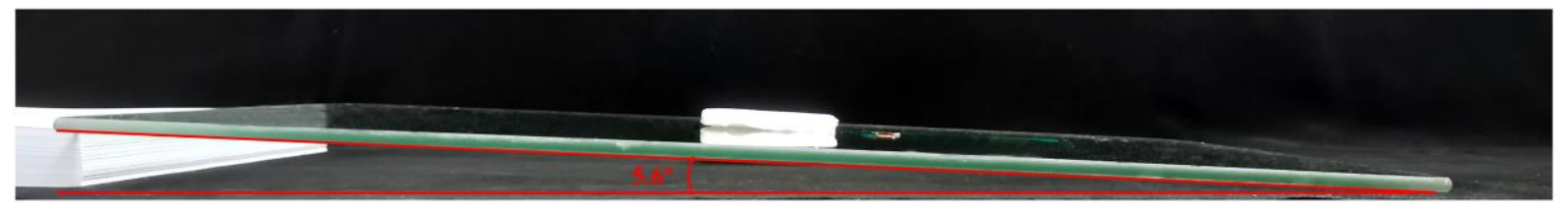

Figure S6. Detection device and rolling angle of hydrophobically modified filter.

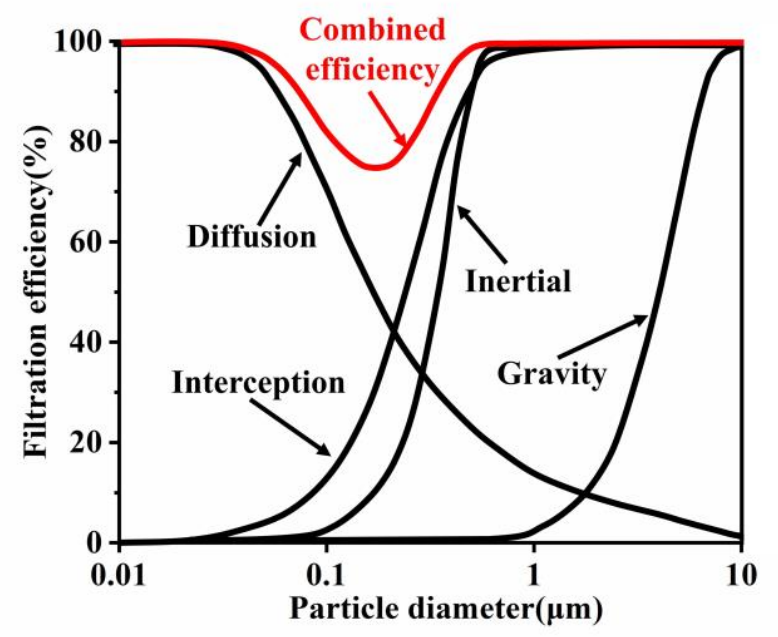

Figure S7. According to classical filtration theory, diagram of filtration mechanism for PMx with diameter from 0.3 to $10.0 \mu \mathrm{m}$. It mainly includes: Brownian diffusion, interception, inertial impaction, and the gravity effect. 

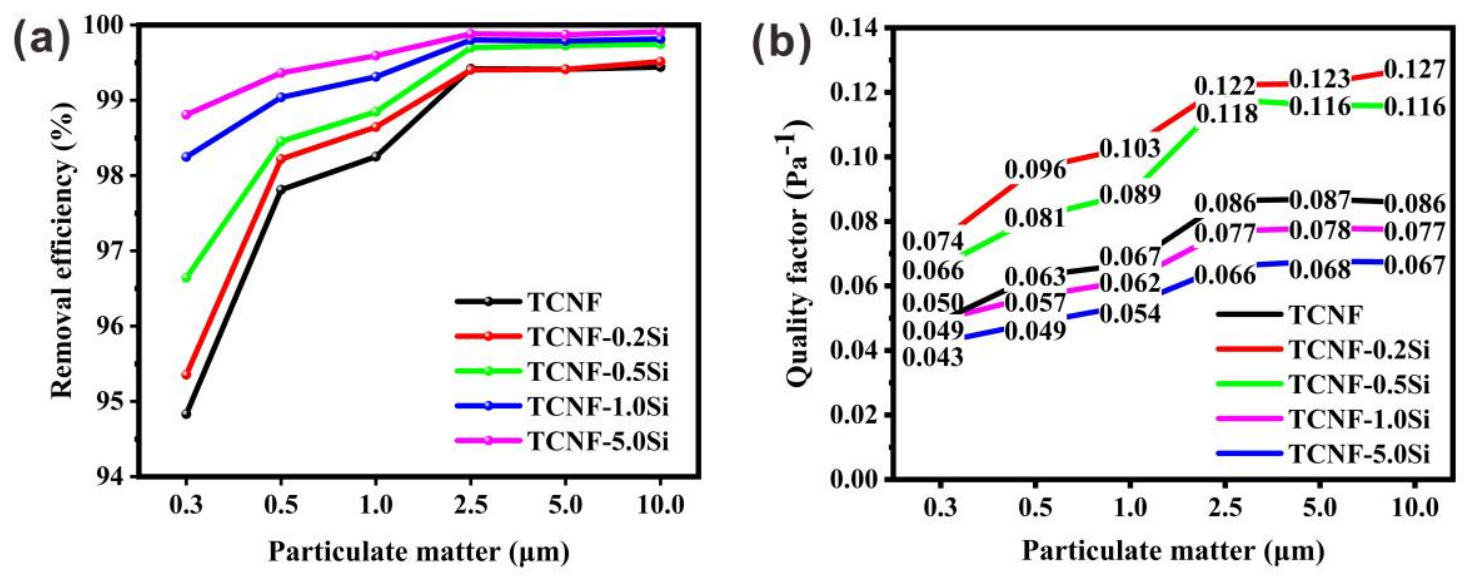

Figure S8. Filtration efficiency and quality factors for oily particulate matter. ( $\Delta \mathrm{P}$ has been explained) (a) Filtration efficiency; (b) Quality factors.

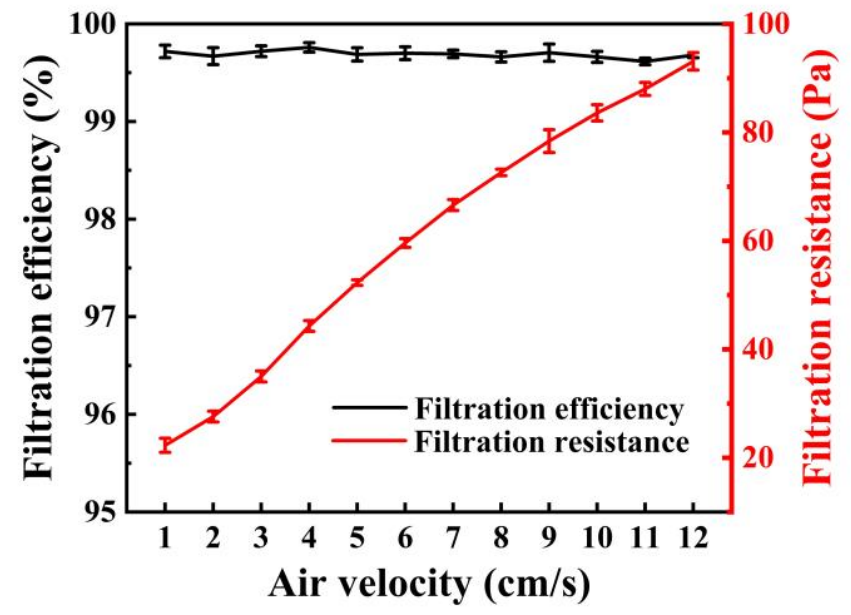

Figure S9. Filtration efficiency and filtration resistance of the filter under different wind speed conditions. 

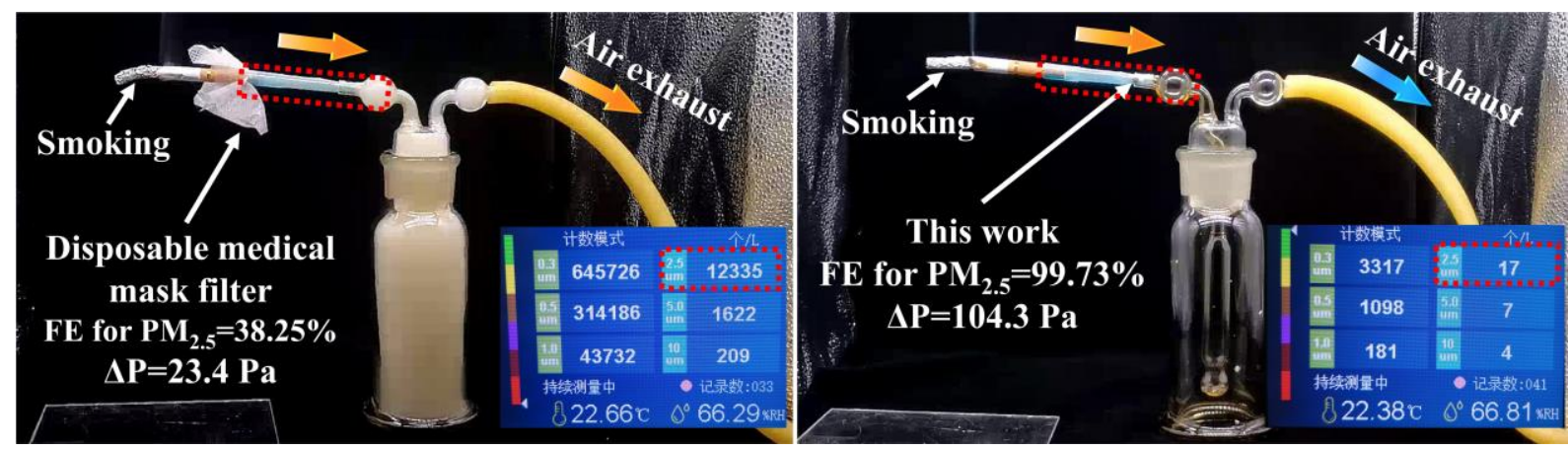

Figure S10. The comparative photograph of the filtering effect of disposable medical surgical mask filter elements and CNF-Si. 